ISSN = 1980-993X - doi:10.4136/1980-993X
www.ambi-agua.net
E-mail: ambi-agua@agro.unitau.br
Tel.: (12) 3625-4212

\title{
Avaliação espaço-temporal da qualidade da água e simulação de autodepuração na bacia hidrográfica do córrego São Simão, SP
}

(http://dx.doi.org/10.4136/ambi-agua.894)

\author{
Julio César de Souza Inácio Gonçalves ${ }^{1}$; Diego de Souza Sardinha²; \\ Antonio Donizetti Gonçalves de Souza ${ }^{2}$; André Luis Bigaram Dibiazi ${ }^{3}$; \\ Letícia Hirata Godoy ${ }^{4}$; Fabiano Tomazini da Conceição ${ }^{4}$

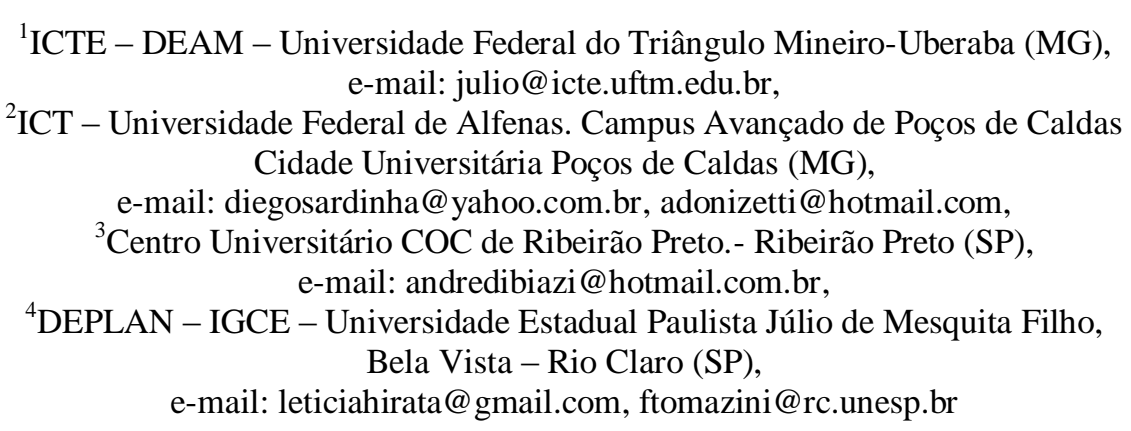

RESUMO

Neste trabalho foram avaliadas as águas fluviais da bacia hidrográfica do córrego São Simão (SP). Para isso, seis pontos de coleta foram estabelecidos e realizaram-se doze coletas de água durante os meses de março, maio, junho, julho, agosto, setembro, outubro, novembro e dezembro de 2005, e janeiro, fevereiro e março de 2006, analisando as seguintes variáveis: vazão, temperatura, turbidez, $\mathrm{pH}$, condutividade, oxigênio dissolvido, alcalinidade, cloreto e sólidos totais em suspensão. A simulação do processo de autodepuração foi realizada com o uso do modelo de Streeter-Phelps, o qual relaciona a variação do déficit de oxigênio dissolvido com o perfil longitudinal do rio. As características do córrego São Simão próximo à sua nascente até a cidade de São Simão permitem concluir que há pouca interferência na sua qualidade. Porém, a falta de tratamento para o esgoto doméstico na cidade de São Simão piora a qualidade da água e intensifica o processo de degradação do córrego São Simão. O modelo de Streeter \& Phelps permitiu identificar as zonas de autodepuração do córrego São Simão e indicou a necessidade de tratamento de esgotos em nível primário, com eficiência de $30 \%$.

Palavras-chave: Avaliação da qualidade da água; esgotos domésticos; modelagem matemática de autodepuração.

\section{Water quality spatial and temporal evaluation and auto-purification simulation from the São Simão stream watershed, SP}

\section{ABSTRACT}

This study evaluated the water of São Simão stream watershed. For this, six sampling points were established and twelve samples of water were collected during the months of March, May, June, July, August, September, October, November, and December of 2005 and January, February, and March of 2006. The following variables were analyzed: discharge, temperature, turbidity, $\mathrm{pH}$, electrical conductivity (EC), dissolved oxygen (DO), alkalinity, chloride and TSS (total suspended solids). The Streter \& Phelps model which correlates the variation of the deficit oxygen with the distance was applied to evaluate the São Simão stream auto-purification. The 
GONÇALVES, J. C. S. I.; SARDINHA, D. S.; SOUZA, A. D. G.; DIBIAZI, A. L. B.; GODOY, L. H.; CONCEIÇÃO, F. T. Avaliação espaço-temporal da qualidade da água e simulação de autodepuração na bacia hidrográfica do córrego São Simão, SP. Ambi-Agua, Taubaté, v. 7, n. 3, p. 141-154, 2012. (http://dx.doi.org/10.4136/ambi-agua.894)

characteristics of the São Simão stream near its spring until it reaches São Simão city allowed concluding that there is low interference in its quality. However, the absence of treatment of domestic wastewater at São Simão city reduced the water quality and increased the degradation process of São Simão stream after passing through the city. The Streeter \& Phelps model allowed identifying the auto-purification zones in this stream and indicated the need for primary wastewater treatment, with an efficiency of $30 \%$.

Keywords: Water quality evaluation; waste water; auto-purification mathematical modeling.

\section{INTRODUÇÃO E OBJETIVO}

Os usos e atividades, irrigação, desmatamento, urbanização, lançamentos pontuais: domésticos e industriais; causam interferências negativas na qualidade e quantidade das águas de um corpo hídrico, consequentemente, a água torna-se indisponível para as necessidades humanas (Souza e Tundisi, 2000; Conceição e Bonotto, 2004; Conceição et al, 2007; Sardinha et al., 2008, 2010; Gonçalves et al., 2009).

Para Pires e Santos (1995), o planejamento e gerenciamento das bacias hidrográficas devem incorporar todos os recursos ambientais da área de drenagem e não apenas o hídrico. Além disso, a abordagem adotada deve integrar os aspectos ambientais, sociais, econômicos e políticos, com ênfase no primeiro, pois a capacidade ambiental de dar suporte ao desenvolvimento possui sempre um limite, a partir do qual todos os outros aspectos serão inevitavelmente afetados. A justificativa para a utilização da bacia hidrográfica como unidade de estudo dá-se pela percepção de que os ecossistemas aquáticos são inteiramente vulneráveis à troca de massa e energia entre si, e principalmente entre os ecossistemas terrestres, sofrendo alterações por consequência da ocupação do solo e atividades neles desenvolvidas (Rocha et al., 2000).

A análise de características físicas, químicas, geológicas e biológicas fornece subsídios relevantes para a caracterização espacial de corpos d'água em bacias hidrográficas. Neste sentido, a análise e interpretação de variáveis de qualidade de água monitoradas no gradiente espaço-temporal, vêm denunciar as condições de uso do solo e as atividades antropogênicas desenvolvidas em uma bacia. Cada bacia hidrográfica deve ter um plano de utilização integrada de recursos hídricos, o qual deve constituir o referencial de todas as decisões e intervenções setoriais nestes recursos (Mota, 1997). O monitoramento da qualidade da água é uma das bases fundamentais de sustentação do gerenciamento integrado (Tundisi, 2005).

No gerenciamento da qualidade da água os modelos matemáticos podem ser utilizados para estimar os focos de poluição existente nas bacias hidrográficas, fornecer estimativas que permitam a tomada de decisões sobre diferentes opções de gerenciamento a longo prazo, e apoiar decisões de gerenciamento a curto prazo. Atualmente há vários estudos que avaliam a qualidade da água e utilizam diversos modelos matemáticos para estimar o déficit da concentração de oxigênio em bacias hidrográficas, dentre eles destacam-se: Gastaldini et al. (2002); USEPA (2004, 2005); Conceição et al. (2007); Sardinha et al. (2008); Gonçalves et al. (2009). Um dos principais modelos matemáticos aplicados à qualidade da água foi desenvolvido por $\mathrm{H}$. S. Streeter e E. B. Phelps em 1925, para o Rio Ohio. Este modelo é utilizado para prever o déficit da concentração de oxigênio em um rio, causado pela descarga de águas residuárias (Von Sperling, 1996).

Atualmente, há grande preocupação em se ter uma abordagem integrada para a gestão de bacias hidrográficas urbanas, pois se tratam de locais que apresentam uma ampla gama de problemas ambientais. Assim, o objetivo deste trabalho consiste na avaliação espaço-temporal da qualidade da água e na simulação de autodepuração na bacia do córrego São Simão, verificando as áreas fortemente degradadas e suas causas, fornecendo subsídios para o seu planejamento e 
GONÇALVES, J. C. S. I.; SARDINHA, D. S.; SOUZA, A. D. G.; DIBIAZI, A. L. B.; GODOY, L. H.; CONCEIÇÃO, F. T. Avaliação espaço-temporal da qualidade da água e simulação de autodepuração na bacia hidrográfica do córrego São Simão, SP. Ambi-Agua, Taubaté, v. 7, n. 3, p. 141-154, 2012. (http://dx.doi.org/10.4136/ambi-agua.894)

gerenciamento, colaborando na busca de soluções para a minimização dos impactos ambientais ocasionados pelas atividades humanas.

\section{MATERIAIS E MÉTODOS}

$\mathrm{Na}$ primeira etapa desse estudo realizou-se a elaboração de um inventário preliminar baseado em pesquisas bibliográficas e em arquivos de órgãos ambientais, técnicos e científicos. A segunda etapa consistiu na caracterização ambiental, com a finalidade de espacializar as informações resultantes da bacia hidrográfica do córrego São Simão. Assim, foram confeccionadas cartas descritivas e interpretativas em meio digital, obtido a partir de fotografias aéreas, imagens de satélite e documentos cartográficos existentes, além de controle em campo utilizando GPS (Global Positioning System). Cartas temáticas foram produzidas através de digitalização em mesa e em tela com posterior edição, usando a seguinte base de dados: cartas 1:50.000 do Instituto Brasileiro de Geografia e Estatística, folhas Cravinhos (IBGE, 1982) e Luis Antônio (IBGE, 1971); cartas 1:100.000 do Instituto Agronômico de Campinas, mapeamento geológico morfoestrutural em parte das folhas de Ribeirão Preto e Descalvado (IAC, 1982); mapas de uso e ocupação do solo (Biota/Fapesp, 2005).

A terceira etapa consistiu na avaliação da qualidade das águas superficiais, onde foram realizadas doze coletas por todo o curso do córrego São Simão (24/03/05 - 07/05/05 - 11/06/05 - 09/07/05 - 09/08/05 - 20/09/05 - 14/10/05 - 27/11/05 - 21/12/05 - 30/01/06 - 28/02/06 31/03/06). A seguinte convenção para os pontos de coleta (Figura 1) será utilizada durante o desenvolvimento deste trabalho: P1 (montante da área urbana); P2 (início da área urbana); P3 (meio da área urbana); P4 (final da área urbana); P5 (jusante da área urbana); e P6 (exutório).

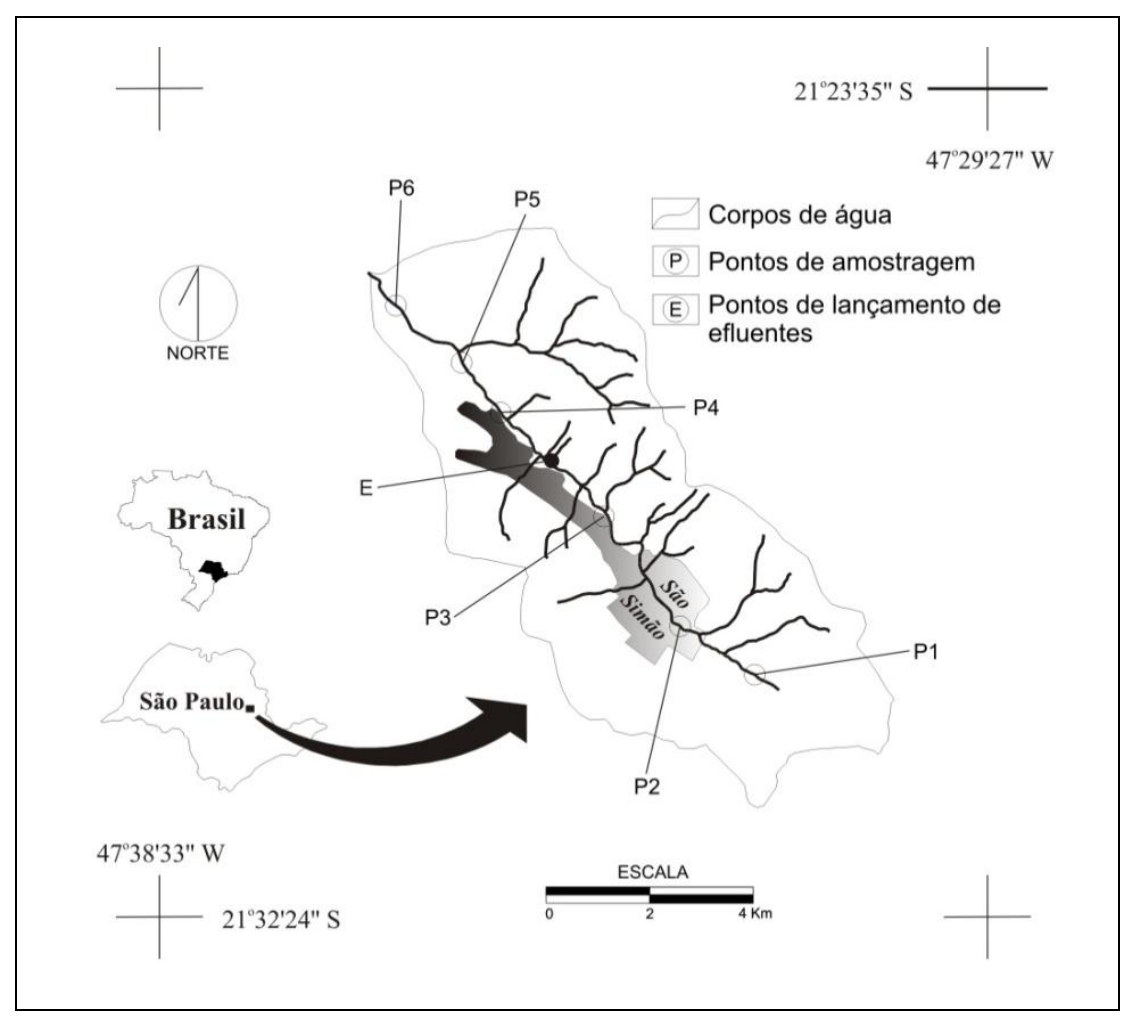

Figura 1. Localização da bacia do córrego São Simão e pontos de amostragem. 
GONÇALVES, J. C. S. I.; SARDINHA, D. S.; SOUZA, A. D. G.; DIBIAZI, A. L. B.; GODOY, L. H.; CONCEIÇÃO, F. T. Avaliação espaço-temporal da qualidade da água e simulação de autodepuração na bacia hidrográfica do córrego São Simão, SP. Ambi-Agua, Taubaté, v. 7, n. 3, p. 141-154, 2012. (http://dx.doi.org/10.4136/ambi-agua.894)

A vazão no ponto de amostragem (P3) foi medida de acordo com a metodologia descrita por (Hermes e Silva, 2004), utilizando-se uma trena, um objeto flutuador e um cronômetro, sendo as variáveis colocadas posteriormente na Equação 1:

$$
Q=\frac{A x D x C}{T}
$$

em que:

$Q=$ vazão $\left(\mathrm{m}^{3} \cdot \mathrm{s}^{-1}\right) ; A=$ área da seção transversal do rio $\left(\mathrm{m}^{2}\right) ; D=$ distância usada para medir a velocidade do escoamento $(\mathrm{m}) ; C=$ coeficiente de correção $(0,8$ para rios com fundo rochoso e 0,9 para rios com fundo lodoso) e $T=$ tempo (s) gasto pelo objeto flutuador para atravessar a distância $D$.

Todas as amostras de águas fluviais foram coletadas no centro da seção transversal, a cerca de $30 \mathrm{~cm}$ de profundidade, com balde previamente lavado com a própria água a ser coletada. Amostras foram armazenadas em vasilhames de polietileno, sendo analisadas as seguintes variáveis físico-químicas: temperatura $\left({ }^{\circ} \mathrm{C}\right), \mathrm{pH}$, oxigênio dissolvido - $\mathrm{OD}\left(\mathrm{mg} \cdot \mathrm{L}^{1-}\right)$, turbidez (NTU), condutividade $\left(\mu \mathrm{S} . \mathrm{cm}^{-1}\right)$, sólidos totais em suspensão - STS (mg. $\mathrm{L}^{-1}$ ), alcalinidade $\mathrm{HCO}_{3}{ }^{-}\left(\mathrm{mg} . \mathrm{L}^{-1}\right)$ e cloreto $\mathrm{Cl}^{-}\left(\mathrm{mg} . \mathrm{L}^{-1}\right)$. As leituras de temperatura, $\mathrm{pH}$, condutividade e oxigênio dissolvido, foram realizadas "in situ" através de métodos ponteciométricos (analisador multiparâmetros Vernier). A variável turbidez foi mensurada com turbidímetro da Vernier (0 a $200 \pm 2 \mathrm{NTU}$ ), assim como cloreto (de 0,01 a $100 \pm 0,02 \mathrm{mg} / \mathrm{L}$ ). Os sólidos totais em suspensão foram quantificados pela metodologia gravimétrica (Standard Methods, 1999). A alcalinidade foi determinada pela titulação com ácido sulfúrico $0,01 \mathrm{~N}$ com concentração entre 1 e $500 \pm 0,2$ mg/L (APHA, 1999).

A modelagem de autodepuração com o uso do modelo de Streeter \& Phelps foi desenvolvida a partir da Equação 2:

$$
\frac{d D}{d t}=K_{1} \cdot L-K_{2} \cdot(D)
$$

em que:

$D=$ déficit de oxigênio dissolvido $\left(\mathrm{mg} . \mathrm{L}^{-1}\right) ; t=$ tempo (dia); $K_{l}=$ coeficiente de desoxigenação $\left(\right.$ dia $\left.^{-1}\right) ; L=$ concentração de DBO remanescente no rio $\left(\mathrm{mg} . \mathrm{L}^{-1}\right) ; K_{2}=$ coeficiente de reaeração $\left(\operatorname{dia}^{-1}\right)$.

A solução analítica da Equação 2 é desenvolvida através da Equação 3:

$$
C(t)=C_{s}-\left[\frac{K_{1} \cdot L_{0}}{K_{2}-K_{1}} \cdot\left(e^{-K_{1} \cdot t}-e^{-K_{2} \cdot t}\right)+\left(C_{s}-C_{0}\right) \cdot e^{-K_{2} \cdot t}\right]
$$

Com uso das equações (4), (5) e (6):

$$
\begin{aligned}
C_{0} & =\frac{Q r \cdot O D r+Q e \cdot O D e}{Q r+Q e} \\
L_{0} & =\left(\frac{Q_{r} \cdot D B O_{r}+Q_{e} \cdot D B O_{e}}{Q_{r}+Q_{e}}\right) \cdot \frac{1}{1-e^{-5 \cdot K_{1}}} \\
C_{s} & =\left(1-\frac{H}{9450}\right) \cdot 14,652-4,1022 \cdot T+7,9910 \times 10^{-3} \cdot T^{2}-7,7774 \times 10^{-5} \cdot T^{3}
\end{aligned}
$$


GONÇALVES, J. C. S. I.; SARDINHA, D. S.; SOUZA, A. D. G.; DIBIAZI, A. L. B.; GODOY, L. H.; CONCEIÇÃO, F. T. Avaliação espaço-temporal da qualidade da água e simulação de autodepuração na bacia hidrográfica do córrego São Simão, SP. Ambi-Agua, Taubaté, v. 7, n. 3, p. 141-154, 2012. (http://dx.doi.org/10.4136/ambi-agua.894)

em que:

$C=$ concentração de oxigênio dissolvido $\left(\mathrm{mg} \cdot \mathrm{L}^{-1}\right) ; C s=$ concentração de saturação do oxigênio dissolvido $\left(\mathrm{mg} . \mathrm{L}^{-1}\right) ; H=$ altitude $(\mathrm{m}) ; T=$ temperatura da água $\left({ }^{\circ} \mathrm{C}\right) ; C_{0}=$ concentração inicial de oxigênio logo após a mistura $\left(\mathrm{mg}^{\mathrm{L}} \mathrm{L}^{-1}\right) ; L_{0}=$ demanda última de oxigênio logo após a mistura $\left(\mathrm{mg} . \mathrm{L}^{-1}\right) ; Q r=$ vazão do córrego São Simão $\left(\mathrm{m}^{3} \cdot \mathrm{s}^{-1}\right) ; Q e=$ vazão dos efluentes domésticos $\left(\mathrm{m}^{3} \cdot \mathrm{s}^{-1}\right) ; O D r=$ concentração de oxigênio dissolvido no córrego São Simão (mg/L); $O D e=$ concentração de oxigênio dissolvido nos efluentes domésticos (mg. $\left.\mathrm{L}^{-1}\right)$; $D B O r=$ concentração de $\mathrm{DBO}_{5}$ no córrego São Simão $\left(\mathrm{mg} . \mathrm{L}^{-1}\right) ; \mathrm{DBOe}=$ concentração de $\mathrm{DBO}_{5}$ no efluente doméstico (mg. $\left.\mathrm{L}^{-1}\right)$.

No modelo de Streeter \& Phelps, o valor de degradação/oxidação da matéria orgânica ou coeficiente de desoxigenação $\left(K_{l}\right)$ é representado por uma taxa que pode variar de 0,08 a 0,45 $\left(\mathrm{dia}^{-1}\right)$ (Von Sperling, 1996), sendo utilizado neste trabalho a taxa de 0,40 ( $\mathrm{dia}^{-1}$ ) para o período seco e para o período chuvoso. O valor indicador da capacidade de autodepuração ou coeficiente de reaeração $\left(K_{2}\right)$ foi utilizado como parâmetro de calibração do modelo, uma vez que as equações empíricas e semi-empíricas usadas para a determinação deste coeficiente, as quais incluem a profundidade e a velocidade do escoamento, produzem resultados divergentes. Considerou-se a população atual de 14.406 habitantes para a cidade de São Simão, a vazão de esgoto doméstico bruto gerado na zona urbana de 2.786,62 $\mathrm{m}^{3} \cdot$ dia $^{-1}$ e a carga orgânica de 696,65 $\left(\mathrm{kg} . \mathrm{DBO}_{5}{ }^{-1} \cdot \mathrm{dia}^{-1}\right)$ (IPT, 2006).

$\mathrm{O} K_{2}$ e o $K_{1}$ são influenciados pela temperatura da água. A correção do valor destes coeficientes é descrita pela Equação 7 . Vale salientar que a temperatura de $20^{\circ} \mathrm{C}$ é utilizada como referência.

$$
K=K(20) \Theta^{(T-20)}
$$

em que: $\mathrm{K}=$ constante cinética da reação à temperatura $\mathrm{T}\left(\mathrm{dia}^{-1}\right) ; \mathrm{K}(20)=$ constante cinética da reação à temperatura de $20^{\circ} \mathrm{C} ; \Theta=$ coeficiente de temperatura para a reação (adimensional). Para $\mathrm{K}_{1}, \Theta$ é igual a 1,047 ; já para $\mathrm{K}_{2}, \Theta$ é igual a 1,024 .

\section{RESULTADOS E DISCUSSÕES}

\subsection{Características da área de estudo}

O córrego São Simão (Figura 1), situa-se entre os paralelos $21^{\circ} 23$ '35' ' e 21 32 '24', de latitude Sul e $47^{\circ} 29^{\prime} 27^{\prime \prime}$ e $47^{\circ} 38^{\prime} 33^{\prime}$ ' de longitude W, na região nordeste do Estado de São Paulo, fazendo parte da Unidade de Gerenciamento de Recursos Hídricos do Pardo (UGRHI 04). Sua nascente está localizada a sudeste do município de São Simão (SP) a uma altitude aproximada de $669 \mathrm{~m}$, e sua foz no Rio Tamanduá, $13 \mathrm{~km}$ a noroeste deste município com altitude aproximada de $575 \mathrm{~m}$.

O clima da região da bacia do córrego São Simão é o do tipo Cwa, segundo o sistema Koppen, ou seja, mesotérmico de verão chuvoso e inverno seco. O verão ocorre entre os meses de outubro a março, sendo intensificado entre dezembro e fevereiro, e o inverno entre os meses de maio a setembro, com temperatura variando entre $7^{\circ} \mathrm{C}$ e $30^{\circ} \mathrm{C}$, com média anual de $19^{\circ} \mathrm{C}$ (IPT, 2006). A precipitação pluviométrica média anual entre os anos de 1950 e 2004 foi de 1420,2 $\mathrm{mm}$, sendo janeiro o mês mais chuvoso (média de $287 \mathrm{~mm}$ ) e agosto o mês mais seco (média de $23 \mathrm{~mm}$ ). Em relação às vazões no córrego São Simão, os meses com maior e menor vazão durante o período de amostragem foram março com $0,68 \mathrm{~m}^{3} . \mathrm{s}^{-1}$ e agosto com $0,32 \mathrm{~m}^{3} . \mathrm{s}^{-1}$, respectivamente. A Figura 2 apresenta a precipitação média mensal (a) e a vazão medida durante o período de amostragem (b), com as quais foram definidos os meses de maio, junho, julho, agosto, setembro e outubro como de período seco, e novembro, dezembro, janeiro, fevereiro, março e abril como de período chuvoso. 


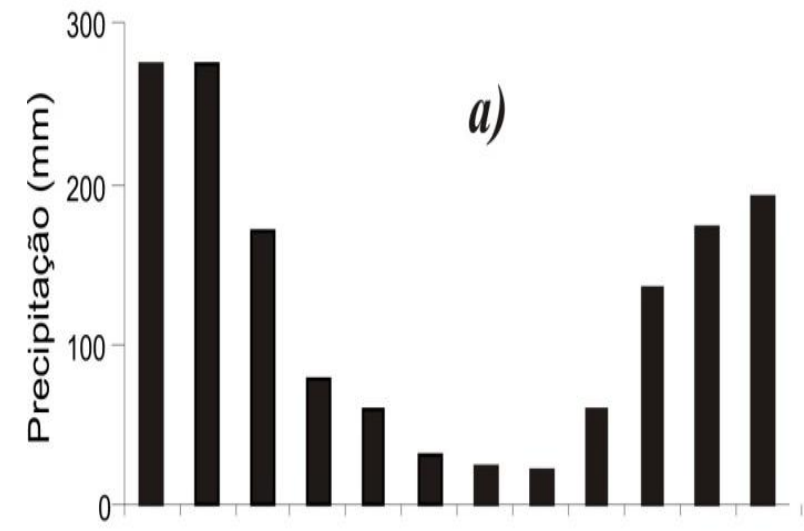

jan fev mar abr mai junh julh ago set out nov dez

\section{Meses}

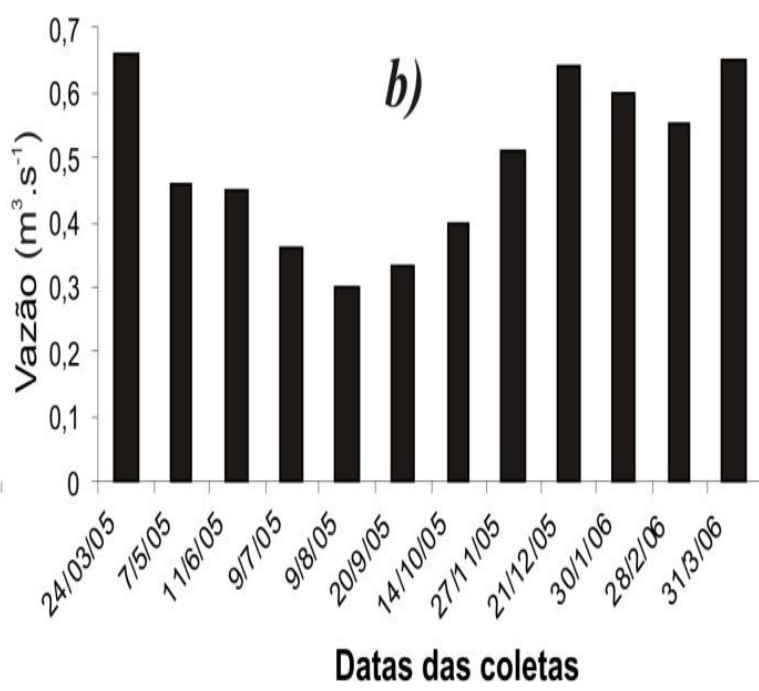

Figura 2. (a) Precipitação média mensal (mm) entre os anos de 1950 e 2004 (IPT, 2006). (b) e vazão $\left(\mathrm{m}^{3} \cdot \mathrm{s}^{-1}\right)$ medida no ponto $(\mathrm{P} 3)$.

A vegetação na bacia caracteriza-se pelas matas mesófilas, de formação caracteristicamente descontínua, que ocorre em condições variadas de clima e solo, tendo caráter semicaducifólio, em decorrência de invernos frios e verões quentes e úmidos. Nas áreas mais bem drenadas próximas à calha dos rios, predominam as Matas Ciliares, restritas a uma estreita faixa descontínua às margens do curso do córrego São Simão (Figura 3a). A economia do Município é voltada principalmente para a atividade rural como agrária, avícola e pecuária, dentre as principais se destacam, a cana-de-açúcar, pinos e eucaliptos, gado de corte e granjas.

Em relação à geomorfologia, São Simão encontra-se em sua maior parte na província das Cuestas Basálticas, conforme definida por Almeida (1964), como sendo esta uma das mais marcantes feições da paisagem paulista com relevo de colinas e morros amplos ou arredondados. $\mathrm{Na}$ área de estudo são encontrados, predominantemente na Formação Serra Geral, o sistema de colinas amplas que apresentam, respectivamente, interflúvios de topos extensos e aplainados com vertentes retilíneas ou convexas, vales abertos e planícies inferiores restritas (Sinelli, 1970).

A bacia do córrego São Simão encontra-se em uma região composta por rochas ígneas e sedimentares pertencentes ao Grupo São Bento (Figura 3b). A Formação Pirambóia apresenta arenitos constituídos basicamente por granulação média a fina com matriz silto-argilosa e estratificação cruzada planar de pequeno a médio porte (Soares e Landim, 1974). Já a Formação Botucatu registra uma sequência de eventos de um ciclo desértico que ocorreu durante o Mesozóico (Schneider et al., 1974). Dominou neste ciclo a sedimentação eólica de areias com granulação fina e muito fina, produzindo corpos de arenitos com boa seleção em grandes cunhas, com estratificação cruzada planar tangencial. O contato entre as formações Botucatu e a Serra Geral faz-se por interdigitação, recobrindo-se os arenitos pelos derrames basálticos (IPT, 1981). A Formação Serra Geral apresenta toda uma completa suíte de tipos litológicos, desde basaltos até riolítos que correspondem a um vulcanismo Mesozóico de bacia intracratônica (Schneider et al., 1974). Dos solos que recobrem a área, os dominantes são os Neossolos Quartzarênicos e Latossolos Roxo, ocorrendo também Latossolos Vermelho-Escuro, Latossolos VermelhoAmarelo e Neossolos Líticos (IAC, 1982). 
GONÇALVES, J. C. S. I.; SARDINHA, D. S.; SOUZA, A. D. G.; DIBIAZI, A. L. B.; GODOY, L. H.; CONCEIÇÃO, F. T. Avaliação espaço-temporal da qualidade da água e simulação de autodepuração na bacia hidrográfica do córrego São Simão, SP. Ambi-Agua, Taubaté, v. 7, n. 3, p. 141-154, 2012. (http://dx.doi.org/10.4136/ambi-agua.894)

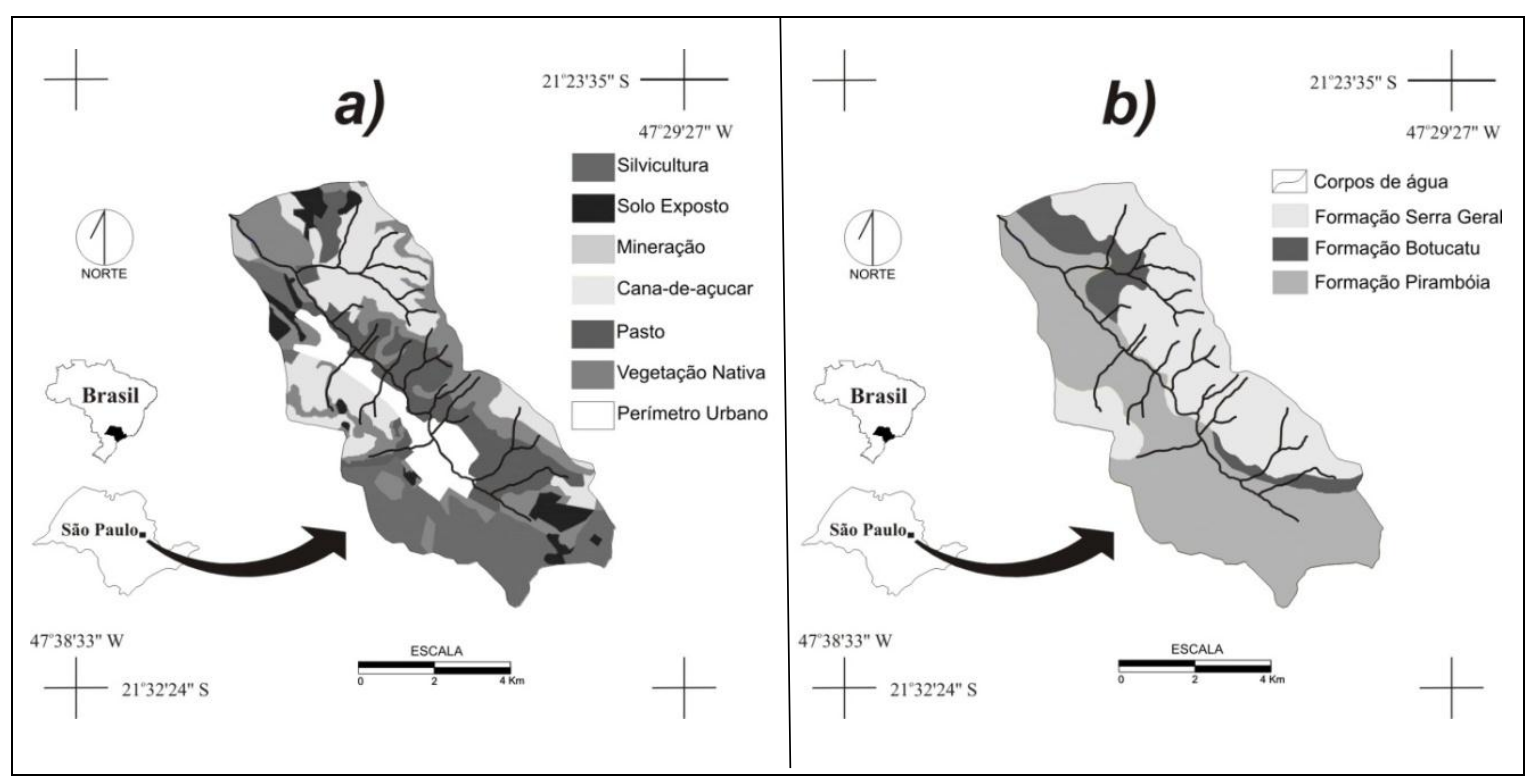

Figura 3. (a) Mapa de uso e ocupação do solo da bacia do córrego São Simão. (b) Mapa geológico da bacia do córrego São Simão.

\subsection{Avaliação espaço-temporal da qualidade da água}

Na Tabela 1 constam os resultados médios obtidos para os parâmetros determinados nas águas fluviais da bacia do córrego São Simão durante o período seco e o período chuvoso. Conforme esperado, a vazão medida no ponto de amostragem (P3) é mais elevada no período chuvoso do que no período seco.

Tabela 1. Média dos parâmetros analisados na bacia do córrego São Simão durante o período seco e chuvoso. P1 (montante da área urbana); P2 (início da área urbana); P3 (meio da área urbana); P4 (final da área urbana); P5 (jusante da área urbana); e P6 (exutório).

\begin{tabular}{|c|c|c|c|c|c|c|c|c|c|}
\hline \multirow[t]{2}{*}{$\begin{array}{l}\text { Ponto de } \\
\text { coleta }\end{array}$} & $\begin{array}{c}\text { Vazão } \\
\left(\mathbf{m}^{3} \cdot \mathbf{s}^{-1}\right)\end{array}$ & $\begin{array}{c}\text { Cond. } \\
\left(\mu \mathrm{S} . \mathrm{cm}^{-1}\right)\end{array}$ & $\begin{array}{c}\text { Temp. } \\
\left({ }^{\circ} \mathrm{C}\right)\end{array}$ & pH & $\begin{array}{c}\text { Turbidez } \\
\text { (NTU) }\end{array}$ & OD & $\begin{array}{r}\mathrm{Cl}^{-} \mathbf{I} \\
(\mathrm{mg} .\end{array}$ & $\begin{array}{l}\mathrm{CO}_{3}^{-} \\
-1)\end{array}$ & STS \\
\hline & \multicolumn{9}{|c|}{ Média do período seco } \\
\hline $\mathrm{P} 1$ & \multirow{6}{*}{0,39} & 22,6 & 20,9 & 4,8 & 1,5 & 6,2 & 0,6 & 1,7 & 4,7 \\
\hline $\mathrm{P} 2$ & & 17,7 & 22,8 & 6,2 & 3,7 & 6,6 & 1,6 & 4,3 & 9,5 \\
\hline P3 & & 37,5 & 23,3 & 6,7 & 5,7 & 6,1 & 3,6 & 9,4 & 5,0 \\
\hline P4 & & 231,1 & 23,4 & 6,4 & 13,5 & 3,3 & 32,7 & 25,4 & 28,7 \\
\hline P5 & & 213,3 & 23,8 & 6,7 & 11,2 & 2,0 & 23,7 & 33,1 & 26,8 \\
\hline \multirow[t]{2}{*}{ P6 } & & 160,7 & 23,3 & 6,5 & 10,0 & 1,7 & 16,4 & 31,6 & 25,2 \\
\hline & \multicolumn{9}{|c|}{ Média do período chuvoso } \\
\hline P1 & \multirow{6}{*}{0,61} & 17,3 & 23,8 & 5,3 & 1,8 & 5,4 & 0,7 & 3,2 & 4,7 \\
\hline $\mathrm{P} 2$ & & 24,3 & 25,5 & 6,5 & 15,5 & 5,3 & 1,7 & 9,9 & 14,2 \\
\hline P3 & & 42,9 & 25,4 & 7,1 & 14,7 & 5,3 & 2,0 & 16,2 & 12,1 \\
\hline $\mathrm{P} 4$ & & 234,4 & 25,3 & 6,7 & 29,3 & 3,8 & 20,4 & 33,1 & 35,0 \\
\hline P5 & & 166,3 & 25,0 & 6,6 & 22,8 & 3,0 & 13,9 & 36,5 & 26,3 \\
\hline P6 & & 119,1 & 24,3 & 6,8 & 27,8 & 2,7 & 5,9 & 32,8 & 24,8 \\
\hline
\end{tabular}


Os menores valores de condutividade elétrica foram obtidos nos pontos P1 e P2, enquanto que os maiores foram caracterizados sempre no ponto P4 logo após a cidade de São Simão (media anual de 232,7 $\mu \mathrm{S} . \mathrm{cm}^{-1}$ - Figura 4a), valor acima do limite superior esperado para águas naturais, isto é, $100 \mu \mathrm{S} . \mathrm{cm}^{-1}$ (Hermes e Silva, 2004). Apesar de que o intemperismo pode elevar a condutividade, acredita-se que os valores mais acentuados devem ser atribuídos principalmente a descargas de efluentes da cidade de São Simão e às atividades agrícolas realizadas na bacia. No ponto P6, os valores de condutividade já se apresentam menores, no entanto, ainda continuam acima do limite superior permitido.

Dentre os pontos estudados, o valor máximo de temperatura da água foi registrado no ponto (P3) no dia $28 / 02 / 2006\left(29^{\circ} \mathrm{C}\right)$, sendo o menor valor obtido no ponto P1 $\left(19^{\circ} \mathrm{C}\right)$ no dia 20/09/2005. Assim como a condutividade, os menores valores médios anuais de temperatura foram encontrados no ponto P1 (Figura 4b), provavelmente devido à vegetação nativa (Figura 3a) que se encontra na nascente do córrego São Simão. Em geral, há uma variação sazonal de temperatura para as águas fluviais da bacia do córrego São Simão, de aproximadamente $10^{\circ} \mathrm{C}$ entre o verão e o inverno.
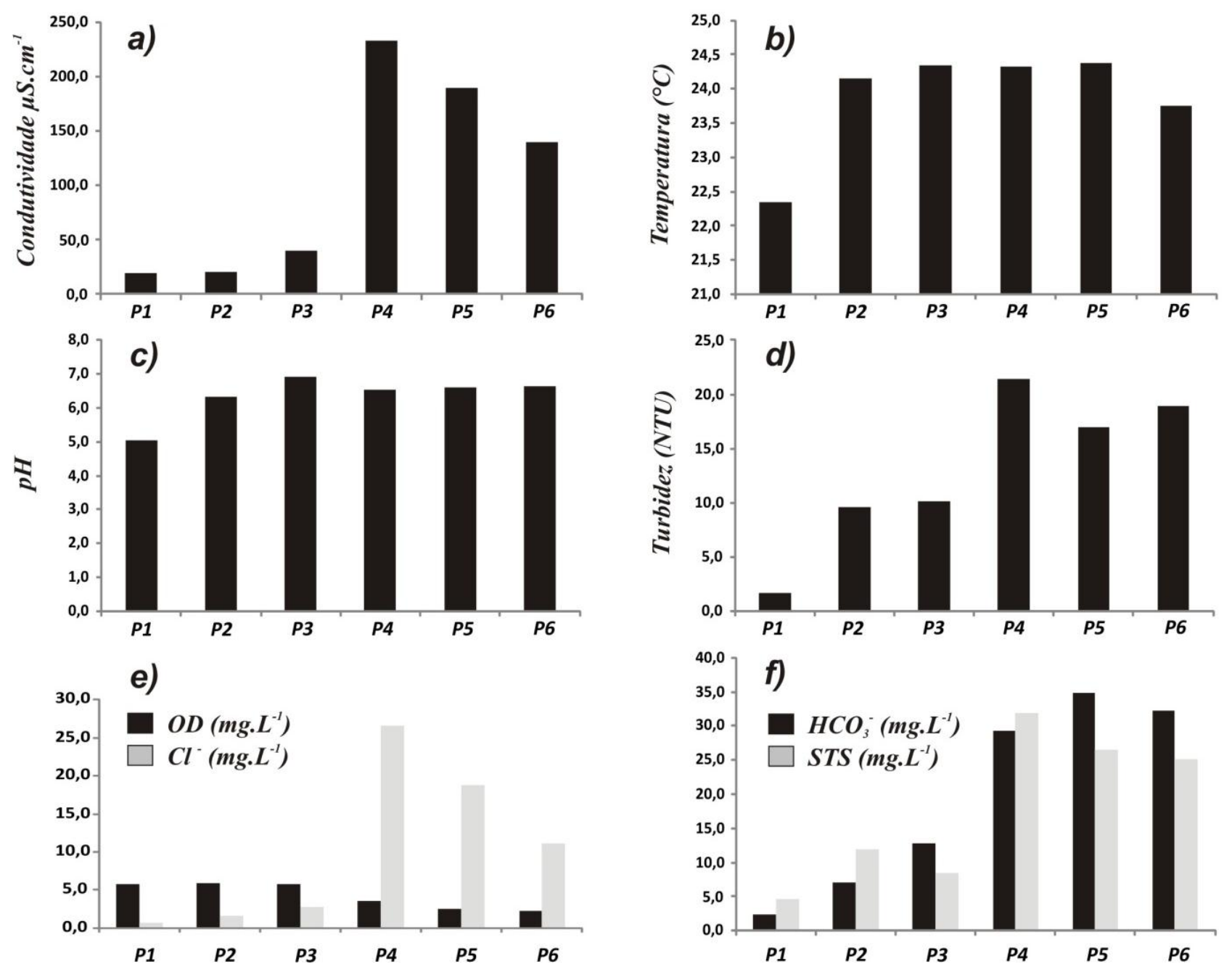

Figura 4. Média dos parâmetros analisados na bacia do córrego São Simão durante todo o período em estudo $(24 / 03 / 2005$ à $31 / 03 / 2006)$. (a) Condutividade $\left(\mu \mathrm{S} . \mathrm{cm}^{-1}\right)$. (b) Temperatura $\left({ }^{\circ} \mathrm{C}\right)$. (c) pH. (d) Turbidez (NTU). (e) Oxigênio dissolvido e cloreto $\left(\mathrm{mg}^{-1} \mathrm{~L}^{-1}\right.$ ). (f) Alcalinidade e sólidos totais em suspensão $\left(\mathrm{mg} \cdot \mathrm{L}^{-1}\right)$. 
GONÇALVES, J. C. S. I.; SARDINHA, D. S.; SOUZA, A. D. G.; DIBIAZI, A. L. B.; GODOY, L. H.; CONCEIÇÃO, F. T. Avaliação espaço-temporal da qualidade da água e simulação de autodepuração na bacia hidrográfica do córrego São Simão, SP. Ambi-Agua, Taubaté, v. 7, n. 3, p. 141-154, 2012. (http://dx.doi.org/10.4136/ambi-agua.894)

$\mathrm{O}$ pH é governado pelo equilíbrio do dióxido de carbono-bicarbonato e carbonatos. $\mathrm{Na}$ bacia, os valores obtidos na maioria dos pontos de amostragem indicam que as águas são geralmente neutras, encontrando-se dentro da faixa de proteção da vida aquática, segundo a Legislação Federal (Resolução CONAMA n ${ }^{\circ}$ 357/05) para rios de Classe 4, conforme são enquadrados os rios da bacia do córrego São Simão. Apenas o ponto (P1) encontraram-se valores de $\mathrm{pH}$ abaixo da Legislação (média anual de 5,1 - Figura 4c).

Os valores de turbidez registraram um aumento ao longo do curso principal do córrego São Simão (Figura 4d). No período chuvoso, os valores de turbidez aumentam, em todos os pontos amostrados, em relação ao período seco (variação máxima de 17,8 NTU). O uso do solo (pasto, silvicultura, solo exposto e cana de açúcar), as características geológicas da bacia (principais tributários localizados em rochas da Formação Serra Geral, que conferem um desnível em relação às Rochas areníticas da Formação Botucatu e Pirambóia, onde se encontra a calha principal do córrego São Simão), além da entrada de efluentes ao passar pela área urbana de São Simão, podem estar contribuindo para o aumento nos valores de turbidez.

A atmosfera e a fotossíntese são as principais fontes de oxigênio para as águas fluviais. Por outro lado, as perdas de oxigênio se devem ao consumo pela decomposição da matéria orgânica, trocas para a atmosfera, respiração de organismos aquáticos e oxidação de íons metálicos (Esteves, 1998). Como pode ser observado na Tabela 1, há uma variação dos valores de oxigênio dissolvido em todos os pontos de amostragem em relação à época de chuva e a época seca. Em geral, os maiores valores de oxigênio dissolvido foram obtidos nos pontos P1, P2 e P3, e são mais elevados no período seco do que no período chuvoso. Fato que pode ser atribuído ao aumento da temperatura da água na época de chuva (verão), ocasionando menor solubilidade de gases (oxigênio dissolvido) na água. O inverso ocorre nos pontos P4, P5 e P6, onde há o aumento da vazão na época de chuva e, consequentemente, maior capacidade de diluição dos efluentes (maiores concentrações de OD).

A presença de cloreto nas águas naturais se deve à alteração das rochas, dentre outros fatores (CETESB, 2005). A bacia do córrego São Simão não possui rochas que tenham cloreto como constituinte principal de seus minerais, neste sentido a entrada natural deste elemento pode ser descartada. As concentrações de cloreto aumentam ao longo do curso do córrego São Simão, principalmente após a passagem pela área urbana do município, maiores concentrações no ponto P4 (Figura 4e). No período seco as concentrações de cloreto são maiores que no período chuvoso (variação máxima de $12,3 \mathrm{mg} . \mathrm{L}^{-1}$ ), provavelmente devido ao menor efeito de diluição no período chuvoso.

Na maioria das coletas, os valores de sólidos totais em suspensão (STS) aumentam ao longo do córrego São Simão. Os maiores e menores valores de STS sempre foram encontrados nos pontos P4 e P1, respectivamente. Os valores de STS aumentam na época chuvosa (média de 19,51 mg. $\mathrm{L}^{-1}$ ) comparado com a época de seca (média de $16,65 \mathrm{mg} . \mathrm{L}^{-1}$ ), mesmo comportamento da vazão, indicando uma maior descarga durante esta época, em acordo com a maioria dos rios mundiais (Berner e Berner, 1996; Conceição e Bonotto, 2004; Conceição et al., 2007). O aumento dos valores de STS na época chuvosa pode ser atribuído ao maior arraste de sedimentos pela erosão laminar que é muito acentuada neste período.

O mesmo comportamento para sólidos totais em suspensão (STS) foi observado para as amostras de alcalinidade $\left(\mathrm{HCO}_{3}{ }^{-}\right)$. A alcalinidade decorre da presença de carbonatos, bicarbonatos e hidróxidos, quase sempre alcalinos ou alcalino-terrosos (sódio, potássio, cálcio, magnésio, etc.) (Wetzel, 1983). A atuação dos processos de intemperismo nos minerais formadores das rochas da bacia, e consequente erosão laminar no período chuvoso, pode estar influenciando as concentrações de $\mathrm{HCO}_{3}{ }^{-}$nas águas superficiais da bacia. Em geral, $\mathrm{H}^{+}, \mathrm{Na}^{+} \mathrm{e}$ $\mathrm{Ca}^{2+}$ podem ser liberados pela hidrólise da albita $\left(2 \mathrm{NaAlSi}_{3} \mathrm{O}_{8}+9 \mathrm{H}_{2} \mathrm{O}+2 \mathrm{H}^{+} \rightarrow \mathrm{Al}_{2} \mathrm{Si}_{2} \mathrm{O}_{5}(\mathrm{OH})_{4}\right.$ $\left.+2 \mathrm{Na}^{+}+4 \mathrm{H}_{4} \mathrm{SiO}_{4}\right)$ e anortita $\left(\mathrm{CaAl}_{2} \mathrm{Si}_{2} \mathrm{O}_{8}+\mathrm{H}_{2} \mathrm{O}+2 \mathrm{H}^{+} \rightarrow \mathrm{Al}_{2} \mathrm{Si}_{2} \mathrm{O}_{5}(\mathrm{OH})_{4}+\mathrm{Ca}^{+}\right), \mathrm{H}^{+}$e $\mathrm{K}^{+}$pela 
GONÇALVES, J. C. S. I.; SARDINHA, D. S.; SOUZA, A. D. G.; DIBIAZI, A. L. B.; GODOY, L. H.; CONCEIÇÃO, F. T. Avaliação espaço-temporal da qualidade da água e simulação de autodepuração na bacia hidrográfica do córrego São Simão, SP. Ambi-Agua, Taubaté, v. 7, n. 3, p. 141-154, 2012. (http://dx.doi.org/10.4136/ambi-agua.894)

hidrólise de microclínio $\left(2 \mathrm{KAlSi}_{3} \mathrm{O}_{8}+9 \mathrm{H}_{2} \mathrm{O}+2 \mathrm{H}^{+} \rightarrow \mathrm{Al}_{2} \mathrm{Si}_{2} \mathrm{O}_{5}(\mathrm{OH})_{4}+2 \mathrm{~K}^{+}+4 \mathrm{H}_{4} \mathrm{SiO}_{4}\right)$. Os efluentes gerados pelo município de São Simão também podem estar influenciando nas concentrações deste parâmetro.

\subsection{Autodepuração no Córrego São Simão}

Como se pode observar na Figura 5, o modelo de Streeter \& Phelps de autodepuração mostrou-se bastante acurado neste estudo. Os dados relativos ao período chuvoso, maior volume de água e velocidade de escoamento no córrego São Simão (Figura 5), demonstram um maior prolongamento na curva de autodepuração, bem diferente ao observado para o período seco. As discussões, referentes à aplicação do modelo Streeter \& Phelps neste trabalho, são feitas para o período crítico ou período seco (menor vazão e menor velocidade de escoamento), onde foi possível delimitar as diferentes zonas de autodepuração que envolve o córrego São Simão nesta época do ano (Figura 5), ou seja, a zona de águas limpas, de degradação, de decomposição ativa e de recuperação.

Os valores de $K_{2}$ obtidos pela calibração do modelo, para o período seco e chuvoso, são de 1,0 e $0,8 \mathrm{dia}^{-1}$, respectivamente.

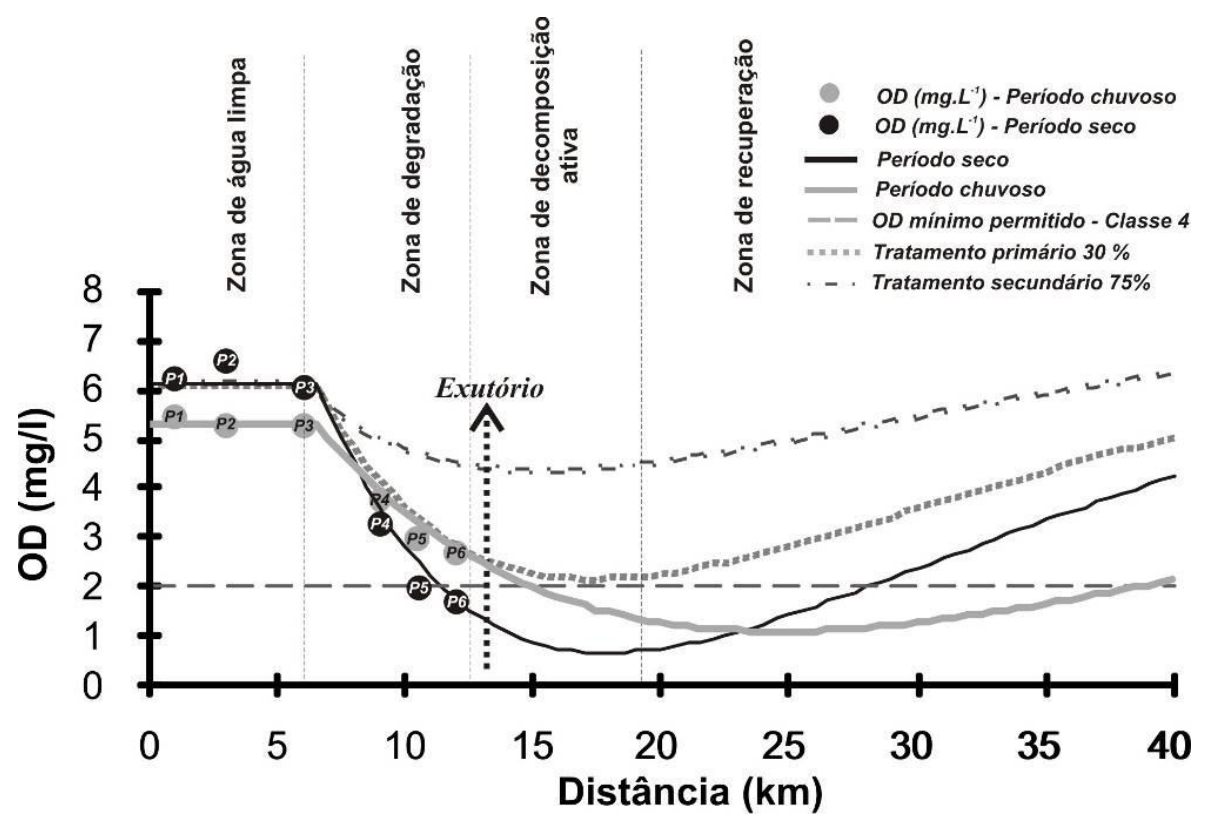

Figura 5. Modelagem de autodepuração no córrego São Simão para o período chuvoso, nas condições atuais, e para o período seco (crítico) nas condições atuais, com tratamento de esgotos primário e secundário com eficiência de $35 \%$ e $75 \%$ respectivamente.

O córrego São Simão, antes da cidade de São Simão, onde se localiza o ponto P1, está situado na zona de águas limpas, onde seu ecossistema encontra-se em estado de equilíbrio e com melhor qualidade da água. A região da nascente do córrego São Simão localiza-se em uma das poucas áreas de vegetação nativa (matas mesófilas - Figura 3a). Conforme suas águas escoam no sentido da área urbana da cidade de São Simão, observa-se uma transição de vegetação nativa para vegetação rasteira, devido à introdução de pastos (pecuária - Figura 3a), proporcionando um aumento da quantidade de areia em seu leito. Os pontos P2 e P3, início e centro da área urbana do município de São Simão, respectivamente, também estão situados na zona de águas limpas, as características da nascente, o desnível topográfico e a ausência de fontes pontuais de efluentes, mantém a boa oxigenação das águas nestes pontos. 
GONÇALVES, J. C. S. I.; SARDINHA, D. S.; SOUZA, A. D. G.; DIBIAZI, A. L. B.; GODOY, L. H.; CONCEIÇÃO, F. T. Avaliação espaço-temporal da qualidade da água e simulação de autodepuração na bacia hidrográfica do córrego São Simão, SP. Ambi-Agua, Taubaté, v. 7, n. 3, p. 141-154, 2012. (http://dx.doi.org/10.4136/ambi-agua.894)

A cidade de São Simão possui 14.406 habitantes e utiliza água para abastecimento de sua população através de captação subterrânea (86\%) e superficial no córrego São Simão (16\%), atendendo $97,5 \%$ da população municipal. A rede de coleta de esgotos atende 95,0\% da população, onde são lançados in natura ao longo do córrego São Simão (vazão de esgoto doméstico de 2,786, $62 \mathrm{~m}^{3} \cdot \mathrm{dia}^{-1}$ ), alterando a qualidade de água, começando aí à zona de degradação (carga orgânica de $696,65 \mathrm{~kg} \mathrm{DBO}_{5}{ }^{-1} \cdot \operatorname{dia}^{-1}$ ), onde o equilíbrio do ecossistema aquático é afetado pela alta concentração de matéria orgânica (Figura 5). Assim, o córrego São Simão entra na zona de degradação (pontos P4, P5 e P6), região onde a qualidade da água apresenta-se em seu estado mais deteriorado (como já caracterizado pelos parâmetros discutidos neste trabalho), provavelmente devido à grande atividade microbiana responsável pela decomposição da matéria orgânica. Nesta região, observou-se que as águas do córrego São Simão possuem forte odor e coloração cinza, com grande quantidade de matéria em suspensão (óleos, espumas e larvas de insetos).

Ao fim da área urbana de São Simão (próximo ao exutório), notou-se a degradação total do córrego São Simão, pois este se encontra na zona de decomposição ativa, com odor muito forte (provavelmente devido há produção de gás sulfídrico gerado pelo lodo de fundo) e aspecto turvo (devido aos sólidos presentes nos esgotos), com alto índice de larvas de insetos, além da presença de óleos e espumas. O córrego São Simão entra na zona de recuperação a aproximadamente $18 \mathrm{~km}$ após o lançamento dos efluentes. Neste caso, a distância necessária para a autodepuração é maior que a distância física do rio, que necessitaria de, pelo menos, mais $18 \mathrm{~km}$ após sua foz para que suas águas voltem a possuir uma concentração de oxigênio dissolvido acima de $2 \mathrm{mg} / \mathrm{L}$, valor recomendado pela Resolução CONAMA 357/05 (Brasil, 2005) para a Classe de seu Enquadramento (Classe 4).

Para que o córrego São Simão possua sempre valores de oxigênio dissolvido acima de 2 $\mathrm{mg} / \mathrm{L}$, torna-se necessário que seja realizado algum tipo de tratamento de efluente antes de seu lançamento no rio. Se a cidade de São Simão possuísse uma estação de tratamento primária de efluentes, com eficiência entre 30 e $40 \%$, a concentração de oxigênio no córrego São Simão ficaria acima de $2 \mathrm{mg} / \mathrm{L}$, como pode ser visto na Figura 5. Assim, como a alternativa de eficiência de 30\% mostrou-se satisfatória, não há necessidade de se investigar alternativas de maior eficiência que, provavelmente, teriam maior custo. Contudo, sempre se deve ter em mente a Resolução CONAMA 357/05 (Brasil, 2005), que preconiza que os efluentes tratados devem possuir DBO máxima de $60 \mathrm{mg} / \mathrm{L}$, eficiência mínima de 80\%, além é claro de não provocarem a alteração da Classe de Enquadramento de um corpo d'água.

\section{CONCLUSÕES}

Os resultados analisados no córrego São Simão levaram em conta parâmetros que permitiram avaliar alterações espaço-temporais na qualidade das águas fluviais e identificar possíveis impactos ambientais que acontecem na bacia. O córrego São Simão até a cidade de São Simão permanece com suas águas limpas, pois a montante da cidade não há fontes poluidoras. A jusante da cidade, o córrego São Simão passa a receber o lançamento de esgoto doméstico in natura, aumentando a concentração da maior parte dos parâmetros estudados. Além disso, há uma diminuição dos valores médios na concentração de condutividade, oxigênio dissolvido e cloreto da época chuvosa em relação ao período seco, opostamente ao observado para o $\mathrm{pH}$, turbidez, alcalinidade e STS, provavelmente devido à erosão laminar, mais atuante no período chuvoso.

A utilização do modelo de autodepuração de Streeter \& Phelps foi compatível com as amostras experimentais feitas no córrego São Simão. Além disso, o modelo conseguiu identificar as várias zonas de autodepuração do córrego São Simão e indicou a necessidade de tratamento de 
GONÇALVES, J. C. S. I.; SARDINHA, D. S.; SOUZA, A. D. G.; DIBIAZI, A. L. B.; GODOY, L. H.; CONCEIÇÃO, F. T. Avaliação espaço-temporal da qualidade da água e simulação de autodepuração na bacia hidrográfica do córrego São Simão, SP. Ambi-Agua, Taubaté, v. 7, n. 3, p. 141-154, 2012. (http://dx.doi.org/10.4136/ambi-agua.894)

esgotos em nível primário, com eficiência de 30\% de remoção de DBO para que as águas sempre permaneçam com a concentração de oxigênio dissolvido acima de $2 \mathrm{mg} / \mathrm{L}$, valor recomendado para seu enquadramento.

Uma política que englobe o desenvolvimento sócio-econômico em harmonia com o meio ambiente deve ser incentivada na bacia do córrego São Simão, de forma a manter uma boa qualidade da água, protegendo os mananciais de abastecimento de água de São Simão.

\section{AGRADECIMENTOS}

Os autores agradecem a FAPESP (Processos no 05/60299-3 e 05/60298-7) e ao Professor Dr. Osmar Sinelli pelo apoio concedido durante a realização deste trabalho.

\section{REFERÊNCIAS}

ALMEIDA, F. F. M. Fundamentos geológicos do relevo paulista. Boletim do Instituto Geográfico e Geológico, São Paulo, v. 41, p. 167-263, 1964.

AMERICAN PUBLIC HEALTH ASSOCIATION - APHA. Standard methods for the examination of water and wastewater. 20. ed. Washington D.C., 1999. 663 p.

BERNER E. K.; BERNER R. A. Global environment: water, air and geochemical cycles. 1. ed. New York: Prentice Hall, 1996. 367 p.

BRASIL. Ministério do Meio Ambiente. Conselho Nacional do Meio Ambiente - CONAMA. Resolução $\mathbf{N}^{\circ}$ 357, de 17 de março de 2005. Dispõe sobre a classificação dos corpos de água e diretrizes ambientais para o seu enquadramento, bem como estabelece as condições e padrões de lançamento de efluentes, e dá outras providências. Disponível em: http://www.mma.gov.br/port/conama>. Acesso em: 09 ago. 2005.

COMPANHIA DE TECNOLOGIA DE SANEAMENTO AMBIENTAL - CETESB. Variáveis de qualidade das águas. Disponível em: <http://www.cetesb.sp.gov.br>. Acesso em: 19 jun. 2005.

CONCEIÇÃO F. T.; BONOTTO D. M. Weathering rates and anthropogenic influences in a sedimentary basin, São Paulo State, Brazil. Applied Geochemistry, v. 19, n. 4, p. 575591, 2004. http://dx.doi.org/10.1016/j.apgeochem.2003.07.002

CONCEIÇÃO, F. T.; SARDINHA, D. S.; SOUZA, A. D. G.; BONOTTO, D. M. Hydrochemical Relationships at Meio Stream Watershed, São Paulo State, Brazil. Revista Brasileira de Geociências, v. 37, n. 2, p. 389-401, 2007.

ESTEVES, F. A. Fundamentos de Limnologia. 2. ed. Rio de Janeiro: Interciência, 1998. 602p.

GASTALDINI, M. C. C.; SEFFRIN, G. F. F.; PAZ, M. F. Diagnóstico atual e previsão futura da qualidade das águas do Rio Ibicuí utilizando o modelo QUAL2E. Engenharia Sanitária e Ambiental, v. 7, n. 3/4, p. 129 -138, 2002.

GONÇALVES, J. C. S. I.; DIBIAZI, A. L. B.; SOUZA, A. D. G.; PENNER, G. C. O uso do modelo QUAL2K como subsídio à seleção de alternativas de tratamento de esgotos Estudo de Caso: Município de São Simão-SP. Revista Uniara, v. 12, n. 2, p. 37-54, 2009.

HERMES, L. C.; SILVA, A. S. Avaliação da qualidade das águas: manual prático. Brasília: Embrapa Informação Tecnológica, 2004. 55p. 
GONÇALVES, J. C. S. I.; SARDINHA, D. S.; SOUZA, A. D. G.; DIBIAZI, A. L. B.; GODOY, L. H.; CONCEIÇÃO, F. T. Avaliação espaço-temporal da qualidade da água e simulação de autodepuração na bacia hidrográfica do córrego São Simão, SP. Ambi-Agua, Taubaté, v. 7, n. 3, p. 141-154, 2012. (http://dx.doi.org/10.4136/ambi-agua.894)

INSTITUTO AGRONÔMICO DE CAMPINAS - IAC. Carta pedológica semidetalhada do Estado de São Paulo: quadrículas de Descalvado e Ribeirão Preto. 1. ed. São Paulo: Aerofoto Cruzeiro S. A., 1982. Escala: 1:100. 000.

INSTITUTO BRASILEIRO DE GEOGRAFIA E ESTATÍSTICA - IBGE. Folha SF-23-V-C-I-4 Cravinhos/SP. 1. reimpr. Rio de Janeiro, 1982.

INSTITUTO BRASILEIRO DE GEOGRAFIA E ESTATÍSTICA- IBGE. Folha SF-23-V-C-IV2 Luis Antonio/SP. 1. reimpr. Rio de Janeiro, 1971.

INSTITUTO DE PESQUISA TECNOLÓGICA DO ESTADO DE SÃO PAULO - IPT. Mapa Geológico do Estado de São Paulo: desenho no 2. São Paulo, 1981. Escala 1:1000. 000.

INSTITUTO DE PESQUISAS TECNOLÓGICAS DO ESTADO DE SÃO PAULO - IPT. Relatório IPT $\mathbf{n}^{\circ} 90635$ - 205: relatório um da unidade de gerenciamento de recursos hídricos do Pardo (UGRHI - 04). São Paulo, 2006. 255p.

MOTA, S. Introdução à engenharia ambiental. 1. ed. Rio de Janeiro: ABES/AIDIS, 1997. $280 \mathrm{p}$.

PIRES, J. S. R.; SANTOS, J. E. Bacias hidrográficas: integração entre meio ambiente e desenvolvimento. Ciência Hoje, v. 19, n. 110, p. 40-45, 1995.

PROGRAMA DE PESQUISAS EM CARACTERIZAÇÃO, CONSERVAÇÃO E USO SUSTENTÁVEL DA BIODIVERSIDADE DO ESTADO DE SÃO PAULO BIOTA/FAPESP. Atlas Biota. 2005. Disponível em: 〈http://www.biota.org.br/index>. Acesso em 23 jan. 2005.

ROCHA, O.; PIRES, J. S. R.; SANTOS, J. E. A bacia hidrográfica como unidade de estudo e planejamento. In: ESPÍNDOLA, E. L. G.; SILVA, J. S.V.; MARINELLI, C. E.; ABDON, M. M. A bacia hidrográfica do rio Monjolinho: uma abordagem ecossistêmica e a visão interdisciplinar. 1. ed. São Carlos: Rima, 2000. p. 1-16.

SARDINHA, D. S.; BONOTTO, D. M. CONCEIÇÃO, F. T. Weathering rates at Alto Sorocaba basin, Brazil, using U-isotopes and major cations. Environmental Earth Sciences, v. 61, n. 5, p. 1025-1036, 2010. http://dx.doi.org/10.1007/s12665-009-0424-7

SARDINHA, D. S.; CONCEIÇÃO, F. T.; SOUZA, A. D. G.; SILVEIRA, A.; DE JÚLIO, M.; GONÇALVES, J. C. S. I. Avaliação da qualidade da água e autodepuração do Ribeirão do Meio, Leme (SP). Engenharia Sanitária e Ambiental, v. 13, n. 3, p. 329-338, 2008.

SCHNEIDER, R. F.; MUHLMANN, H. E.; MEDEIROS, R. A.; DAEMON, R. F. NOGUEIRA, A. A. Revisão estratigráfica da bacia do Paraná. In: CONGRESSO BRASILEIRO DE GEOLOGIA, 28., 1974. Porto Alegre. Anais... Porto Alegre: SBG, 1974. Vol. 1. p. 41-65.

SINELLI, O. Geologia e água subterrânea no município de Ribeirão Preto e adjacências. 1970. 116 f. Tese (Doutorado em Geografia) - Faculdade de Filosofia, Ciências e Letras de Ribeirão Preto, Universidade de São Paulo, Ribeirão Preto, 1970.

SOARES, P. C.; LANDIM, P. M. B. Aspectos da estratigrafia da Bacia do Paraná no seu flanco nordeste. In: CONGRESSO BRASILEIRO DE GEOLOGIA, 28., 1974, Porto Alegre. Anais... Porto Alegre: SBG, 1974. Vol. 1. p. 243-256. 
GONÇALVES, J. C. S. I.; SARDINHA, D. S.; SOUZA, A. D. G.; DIBIAZI, A. L. B.; GODOY, L. H.; CONCEIÇÃO, F. T. Avaliação espaço-temporal da qualidade da água e simulação de autodepuração na bacia hidrográfica do córrego São Simão, SP. Ambi-Agua, Taubaté, v. 7, n. 3, p. 141-154, 2012. (http://dx.doi.org/10.4136/ambi-agua.894)

SOUZA, A. D. G.; TUNDISI, J. G. Hidrogeochemical comparative study of the Jaú and Jacaréguaçu River watersheds, São Paulo, Brazil. Revista Brasileira de Biologia, v. 60, n. 4, p. 563-570, 2000. http://dx.doi.org/10.1590/S0034-71082000000400004

TUNDISI, J. G. Água no século XXI: enfrentando a escassez. 2. ed. São Carlos: Rima, 2005. 248 p.

UNITED STATES. Environmental Protection Agency - USEPA. Total maximum daily load for nutrients Deep Run, Beach Run, and Elizabeth Run Lebanon County, Pennsylvania. Philadelphia, 2004. 77p.

UNITED STATES. Environmental Protection Agency - USEPA. Modeling report for total maximum daily load for Skippack Creek, Montgomery County, Pennsylvania. Philadelphia, 2005. 108p.

VON SPERLING, M. Introdução à qualidade das águas e ao tratamento de esgotos. 2. ed. Belo Horizonte: UFMG, 1996. 246p.

WETZEL, R. G. Limnology. 2. ed. Rochester: Saunders College Publishing, 1983. 767p. 